\title{
Leadership Training Program for Medical Staff in Belgium
}

\author{
Neree Claes $^{1} \&$ Valérie Brabanders ${ }^{2}$ \\ ${ }^{1}$ Faculty of Medicine and Life Sciences, University Hasselt, Hasselt, Belgium \& Health Care Management, Antwerp \\ Management School, Antwerp, Belgium \& vzw Stijn Dienstencentrum Sint-Gerardus Diepenbeek, Diepenbeek, \\ Belgium \& vzw Wit-Gele Kruis Limburg, Brussels, Belgium \\ ${ }^{2}$ Faculty of Economics and Business, Ku Leuven, Leuven, Belgium \\ Correspondence: Neree Claes, Faculty of Medicine and Life Sciences, University Hasselt, Hasselt, Belgium
}

Received: October 11, 2016

Accepted: November 14, 2016

Online Published: November 15, 2016

doi:10.5430/ijhe.v5n4p281

URL: http://dx.doi.org/10.5430/ijhe.v5n4p281

\begin{abstract}
Today healthcare is facing many challenges in a volatile, uncertain, complex and ambiguous environment. There is a need to develop strong leaders who can cope with these challenges. This article describes the process of a leadership training program for healthcare professionals in Belgium (named 'Clinical Leadership Program' or 'CLeP') in order to develop the future generation of strong healthcare leaders. The process over the past 3 years, refining time frame, content and format \& faculty will be discussed. At the start of 2013 a literature study and round up of existing programs were made. Furthermore, a preliminary program was constructed and adapted by different stakeholders. Their feedback taken into account, CLeP was launched 6 months later. From there, 9 different hospitals and 10 groups fulfilled the program. In total 179 healthcare professionals are educated (100 physicians, 37 nurses and 42other healthcare staff). After the completion of the program, in depth interviews served as an evaluation and suggestion for further development of our program. The 'Clinical Leadership Program' consists of 2 modules spread over 5 days of training, each covering a different theme. These themes incorporate 'Me', 'Team', 'Organization', 'Institution' and 'Societal impact' respectively. The first module covers the first two days, while the second module covers day 3-5. After applying, groups of 20 participants follow the 4 months program under the guidance of a senior mentor. They can choose to follow either only the first or both of the modules and whether or not to perform an assignment within their program. In order to develop the future generation of strong healthcare leaders, CLeP was worked out. This article describes the experiences and learnings of our program over the past 3 years. In the future, similar programs will be needed even more.
\end{abstract}

Keywords: Healthcare, Leadership, Training Program, Medical Staff

\section{Introduction}

Today we are living in a VUCA environment, an acronym for Volatility, Uncertainty, Complexity, and Ambiguity (Sturmberg, Joachim P., Martin, C. M. 2003). This environment forces organizations to reinvent their business models, even so in Health Care (HC). HC is dealing with huge challenges: a shortage of health care providers, an aging population with chronical diseases, over burden of tasks, cost cuttings, high quality demands and an increase of innovations. To tackle these challenges there is a need for physicians leaders in order to bring a fundamental change (Mountford, J., Webb, C. 2009). This brings us to the difference between traditional managers who produce predictability and order through planning, organization, control, and problem solving; and in contrast, leaders, who stimulate change through the motivation and alignment of people with an established direction. Warren Bennis (1989), describes the distinction even further: "Leaders are people who do the right things. Managers are people who do things right" (Bennis, W. 1989). There's a profound difference.

A leader in HC should be able to direct its employees towards a common goal. A clear vision is essential in order to achieve desired outcomes and motivate co-workers to improve patient care and adapt to the changing environment (Kotter, J. P. 1998)(Mountford, J., Webb, C. 2008)(Darzi, A. 2010). However, leadership skills are needed for those physicians to fulfill this new role. Physicians are trained in clinical skills during a minimum of 7 years. The knowledge base provided to them during medical education is nearly overwhelming all by itself and it is unfortunately not sufficient once physicians are leading a medical team in a VUCA environment. Medical education typically produces solo practitioners; however, nowadays, if organizations are willing to keep on functioning, clinicians are almost forced to engage in leading and managing systems of health care at all levels, on whatever scale 
- team, department, unit, hospital or health authority (Swanwick, T., \& McKimm, J. 2001). Even more so, leadership is argued to be necessary 'at all levels', so leadership development, assessment and feedback must be provided throughout the education and training of health professionals(Swanwick, T., \& McKimm, J. 2001). Summarized, there is a need for training programs developing leadership skills in HC in order to achieve this. The 'Clinical Leadership Program (CLeP)' proposed in this paper is a way to address the deficits mentioned before and develop well trained leaders who can cope with the current challenges.

Supplementary, it needs a change in corporate culture. HC leaders have to be chosen based upon their superior leadership skills. A lot of $\mathrm{HC}$ leaders - above 50 years of age - were chosen to lead because of productivity, published research, solid clinical skills, or because they were great educators. Sadly, most of these physicians never followed any formal leadership training, but instead learned by observing successful academics but were not formally trained leaders (Heifetz RA. 1994). Often they do not have the skills to form a team resulting in dysfunctional teams which are dealing with conflicts and chaos. However, a questionnaire with $328 \mathrm{HC}$ professionals learned that there is a need for more formal leadership training with explicit attention for leadership development (Van der Wal, M. A., Scheele, F., Schönrock-Adema, J., Jaarsma, A. D. C., \& Cohen-Schotanus, J. 2015). Stoller suggested several features inherent to physician's training that do not promote working in teams: the experience of long and hierarchical training with extended subordination (internship, residency, fellowship); evaluations based on individual performance (licensure, in service, and board certification examinations), extrapolated leadership (extend clinical authority to other areas, such as entering first in an elevator at the hospital), and training based on "deficit thinking" (always trying to find and solve the problem) (James K. Stoller, 2010).

Leadership programs in HC have to focus on transformational leadership with special attention for relations and teams. The latter is more effective than transactional or task focused leadership styles (job completion, deadlines and directives). A significantly positive relation was found between transformational leadership and patient outcomes, staff satisfaction and staff retention (Van der Wal, M. A., Scheele, F., Schönrock-Adema, J., Jaarsma, A. D. C., \& Cohen-Schotanus, J. 2015). The NHS developed an evidence-based behavioral model for Healthcare Leadership (Storey, J., \& Holti, R. 2013). In this model nine leadership skills for HC are defined: sharing the vision, inspiring shared purpose, leading with care, engaging the team, connecting our service, evaluating information, influencing for results, holding accountable and developing capability. These skills are trained in our leadership program. The purpose of this paper is to elaborate this program and propose a way to develop competent HC leaders. Besides the need for such a program, its content and format has to be defined. To answer these questions, a study process has been conducted with the release of a 'Clinical Leadership Program (CLeP)' as result. The program is launched multiple times a year and refined with the comments of the former participants. In this article the process of development (3 years) will be described. This program can be a helpful contribution, not only in the health care sphere but also in many other areas where leadership is actual.

\section{Methods}

At the start in 2013 a literature study and round up of existing programs was made by a physician, Phd MBA. A preliminary program was constructed and proposed to different stake holders (6 physicians head of a department, 6 head nurses, 4 professors management of a business school, 3 medical directors, 3 hospital CEO's). Their feedback (time frame, content, format \& faculty) was processed to adapt the program, which was released 6 months later in 2014 and proposed to 17 physicians from 1 hospital. Our program was modularly constructed in different days with each a specific theme; 'Me', 'Team', 'Organization', 'Institution' and 'Societal Impact' (Figure). The first module consists of the first, the second and the third day which cover the themes 'Me', 'Team' and 'Organization' respectively. The second module covers the fourth and the fifth day, which cover the topics 'Institution' and 'Societal Impact'. One year later the full program was offered to other Flemish hospitals. Some hospitals choose the full program while others preferred a reduced program; covering only the first module. In Figure the evolution of participants and hospitals over the past 3 years is resumed. At the end of every program a structured questionnaire was filled out by the participants. In depth interviews were organized for those suggestions that could be taken into account and contribute positively to the program. This caused different adaptations (time frame, content, format \& faculty) to the program. 


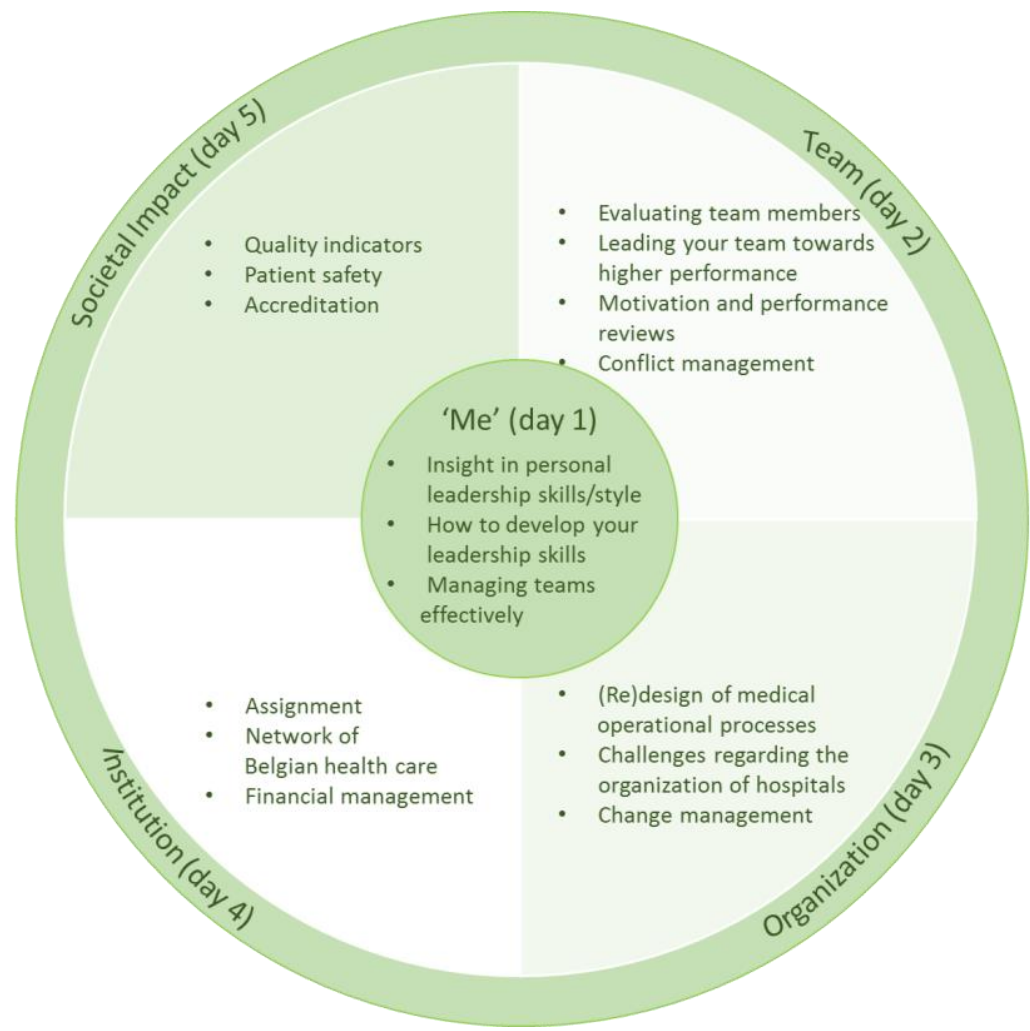

\section{Results}

Figure 1. Modules of the Clinical Leadership Program

\subsection{Participants}

With the group graduating this year, we will have provided physicians $(n=100)$, nurses $(n=37)$, and other HC staff $(n=42)$, leadership skills in order to develop the future generation of strong HC leaders which in turn would benefit patients, teams and hospitals. After every program an evaluation was done. In Figure an overview of the changes (time frame, content and format \& faculty) is given.

\subsection{Time Frame}

The full program is spread over 5 days ( 3 consecutive days in the first module +2 consecutive days in the second module) at a residential location over a period of 4 months. A maximum of 20 participants per module can apply for the program.

\subsection{Content}

The first day is organized around personality and personal leadership skills of our physicians. The program contains personality tests which are shared in the group. In the afternoon, team management and leading a meeting is instructed. The second day is organized around performance and dynamics within the team itself, while the first day has a stronger focus on the particular position of a physician in its team. Effectively managing teams and evaluating team members is considered as well. Regarding the evaluation, motivation and performance reviews are instructed using 'Appraisal \& Assessment' techniques. Moreover, it is shown how the use of a balanced scorecard can contribute to high performance teams. Finally, at the end of the second day, conflict management is discussed. Furthermore, on the third day operational processes, organization of hospitals and change management is taught. At the end of the first module physicians are instructed to perform an assignment to their department. In this assignment they have to prove and use the content learned during the first 3 days. During the 4 months they are mentored by a clinical professor with an executive leadership assignment. The first half of the fourth day, the physicians have to present their assignments to the whole group and some faculty members in 5 minutes. After this brief presentation, participants are questioned about their assignments and the curriculum of the first module. In the afternoon, the network of the Belgian HC and financial hospital management are discussed. On the fifth day, the physicians are taught how to autonomously develop, use and implement quality indicators. In the afternoon, patient safety and accreditation of hospitals is instructed. 


\subsection{Format \& Faculty}

A mix between models and case studies are presented to participants. A multidisciplinary staff is formed: a clinical professor with an executive leadership assignment (mentor), a medical director of a hospital, two management professors of the business school (performance management and Organization \& Networking), a consultant conflict management, an academic professor finance with an executive appointment in Belgian government, a nurse with a $\mathrm{PhD}$ in Patient Safety and the CEO/CMO of the hospital. Yearly a reunion is organized to give an update of recent literature and to stimulate life-time learning of our group CLeP-physicians.

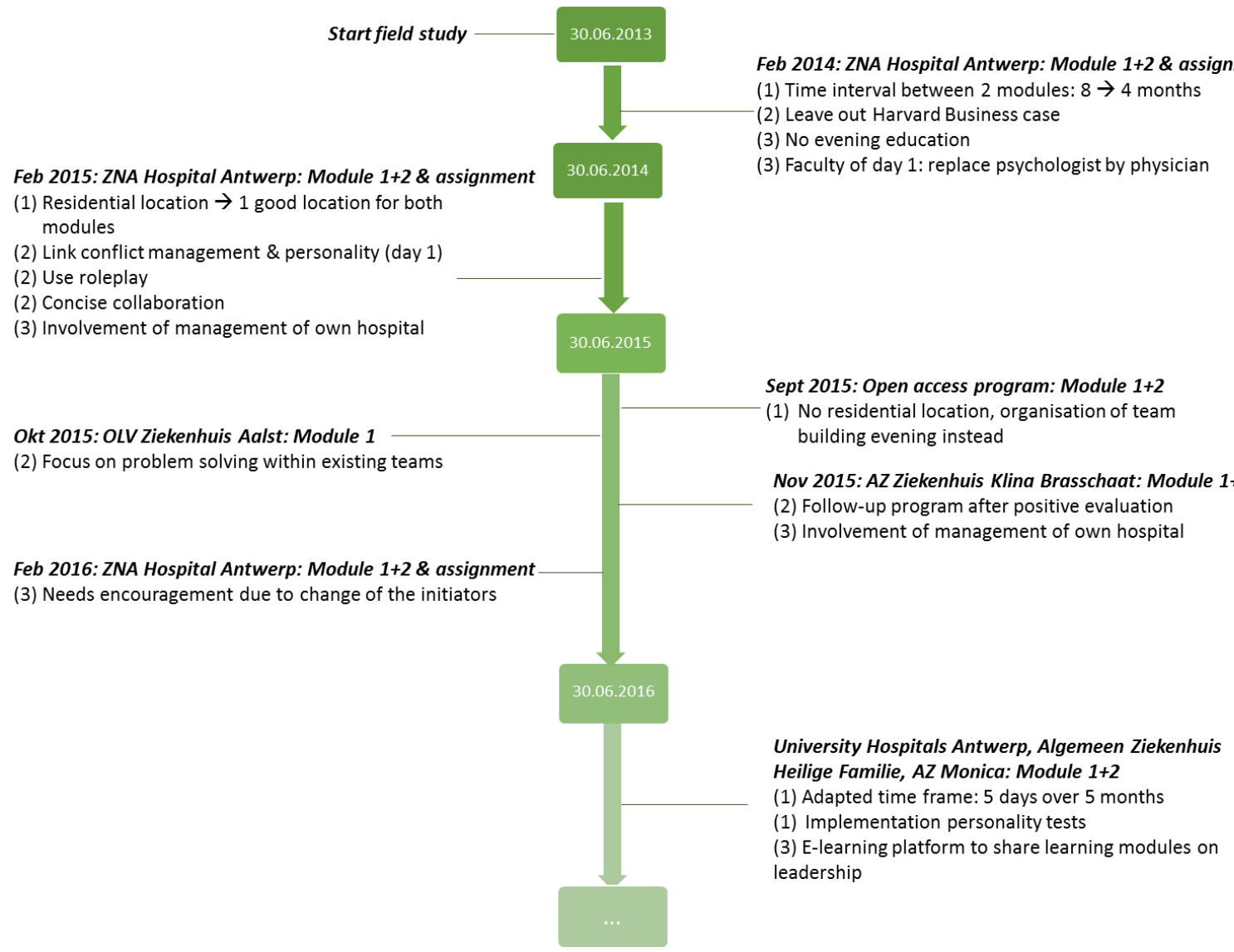

Note: Adaptations in time frame, content, format \& faculty are indicated 1,2, and 3 respectively. When a number is not mentionned, no changes were applied.

Figure 2. Evolution of the Clinical Leadership Program

\section{Conclusion}

This article describes the process of a leadership program of HC professionals in Belgium - named CLeP - in order to develop the future generation of strong HC leaders. To achieve this, CLeP includes a 4 months program under the guidance of a senior mentor. This article describes the experiences and learnings of the past 3 years of our program.

Our program is based on Schwartz' three recommendations for physician leadership: local, long-term instruction and led by physicians (Schwartz Richard W, Pogge, Caroline R., Gillis, Susan A., Holsinger, J. W.). For the long-term follow-up a networking community with alumni is started with a yearly reunion with guest speakers. Supplementary an e-community via Linked-in is built. And finally the publication of a textbook on leadership in HC with different cases of our community members has recently been published (Claes, N. 2016). The network community and our e-community forms an opportunity for emerging leaders to reinforce relationships among classmates and to extend learning (Stoller, K. 2013).

Stoller suggests that a mature leadership development program should include three complementary experiences for emerging leaders: didactic teaching, mentorship and experiential leadership opportunities. In our program these three experiences are included so that our leaders have the opportunity to enrich their leadership skills and gain experience. In previous research, it has been confirmed that physician leaders believed that mentorship and role modeling played 
a significant role in their career development (Taylor, C. a., Taylor, J. C., \& Stoller, J. K. 2009). Furthermore we provide a safe, constructive environment for them to receive feedback and ask any questions if required. To make the link with the real day-to-day challenges, an assignment is included, during which the mentor supports and guides the participants. However, we saw that $50 \%$ of the hospitals didn't chose this option. Although it is a necessary opportunity to translate learning into action - especially important given the lack of follow-up support in the workplace (Mountford, J., Webb, C. 2008). Cost saving on the part of the client was the reason for skipping this option.

Our faculty is selected to educate both theoretical models and practical applications on leadership topics. Our team of experts consists of a mix of content specialists, educated by business schools, and genuine health care leaders to ensure that participants can develop an excellent understanding of health care leadership (Stoller, K. 2013). This multidisciplinary approach allows the faculty to blend pedagogic excellence and depth with, for example, the experience and credibility that only physicians can offer for teaching their colleagues. As the mentor is a physician (herself), the distance between mentor-client is reduced, resulting in the creation of a safe environment allowing to advance their soft skills and team functioning.

Our program is organized for senior HC professionals (physicians leading a department, CMO's, head nurses and other HC staff). However, to fundamentally change the way new physicians think, leadership training should start in medical school (Varkey, P., Peloquin, J., Reed, D., Lindor, K., Harris, I. 2009) (Arroliga AC, Huber C, Myers JD, Dieckert JP, W. D. 2014). Currently, little or no attention is given in medical school to train physicians regarding leadership competencies. In this context, an emerging trend is for health-care institutions to offer physician-leadership programs. Recently the Can Meds - a competency-based framework for medical training in order to improve patient care - added collaboration and leadership in their framework (Frank, J. R., Frank, J. R., \& Danoff, D. 2007). Collaboration is reflected broadly, even beyond the context of a formalized health care team.

HC faculties have to invest in training these skills and competences in order to establish adequate leaders since effective clinical leaders and managers need to be nurtured and supported by the organizations and health systems within which they work and learn (Swanwick, T., \& McKimm, J. 2011). For example, clinical case studies could be discussed in class by a multidisciplinary team of HC professionals. This emphasizes the value of team functioning and moves physicians away from the idea of functioning as a solo practitioner towards functioning as a member of a health care team. Furthermore, when both clinical and medical skill sets are developed during graduate medical education, physicians' value added to HC organizations as well as patients increases(Ackerly, D. C., Sangvai, D. G., Udayakumar, K., Shah, B. R., Kalman, N. S., Cho, A. H., ... Dzau, V. J. 2011). The program tries to enhance the quality of clinical leadership in hospital care. It does so by reducing the barriers to participation in clinical leadership as stated by J Daly et al (2014) such as poor communication, poor preparation for leadership roles, curriculum deficiencies at undergraduate level in medicine and health professional courses, inadequate resourcing of development programs, poor interdisciplinary relationships, and poor team work (Daly, J., Jackson, D., Mannix, J., Davidson, P., \& Hutchinson, M. 2014). Those interested in executive leadership could invest in deepening their knowledge after medical graduation. The intensity of leadership education has to be adjusted to the challenges of the appointment: leadership to patient-family, team member, team leader, divisional leader and senior leadership (CMO, CEO or president) (Bohmer, R. 2012). Various leadership development programs have made great progress so far, but unanswered questions still remain about the benefits of formal health care leadership training (James K. Stoller, 2009). For example, a true return on investment analysis of a leadership development program has to be done. Another unanswered question is the financial investment of such a program. During our 4 years we saw several options. Firstly, there is the possibility that the hospital and the physicians split the costs evenly. This 50/50 ratio seems reasonable because both parties make an investment; the hospitals invest in the leadership skills of their personnel, showing that they consider them as a valuable asset. In return, they expect to experience certain advantages. Concerning the physicians; they commit to investing in themselves as a person and in their career. Furthermore, the physicians enroll voluntarily in the program and as they partly paid for it themselves, they feel more responsible and tend to complete the full program more often. Secondly, there is the possibility that the hospital pays for the entire program. However, this is often experienced as quite costly and tends to push towards the reduced format of the program or an inferior location in order to reduce costs. The latter is not a favorable choice. Because self-employed physicians - who spend their costly time for education - want to be invited in a comfortable location. Another negative finding about full hospital funding is accountability of the physicians. Because physicians do not share in the costs, they feel less responsible and tend to drop out of the program. Thirdly, physicians pay $100 \%$ of the costs of the program. The physicians coming from different hospitals participated in our open access program at the 
business school. However, this is not the most popular option resulting in a small number of participants. To answer this financial question a willingness to pay study has to be conducted.

At this moment the program has been followed mostly due to the goodwill of the hospitals. However, multiple motives are possible. Recent studies indicate that by implementing transformational leadership principles, patient care has been improved and an environment wherein nurses have greater commitment to the organization and higher levels of morale and job satisfaction has been fostered (Tomey, A. M. 2009)(Brennan, B., Henrick, S., \& Monturo, C. 2016). Furthermore, a change will be seen due to the demands of accreditation (NIAZ en JCI) were hospital leadership is becoming an essential norm that has to be fulfilled. Just as NIAZ, JCI (Joint Commission International) is an international organization that provides international norms regarding quality improvement and patient safety. JCI devotes a whole chapter to Governance, Leadership, and Direction" (GLD) (Frank, J. R., Frank, J. R., \& Danoff, D. 2009) indicating the value they dedicate to leadership \& leadership development. Niaz-Qmentum recognizes the importance of leadership since they state leadership just below governance, in their actual norm set (Ackerly, D. C., Sangvai, D. G., Udayakumar, K., Shah, B. R., Kalman, N. S., Cho, A. H., .. Dzau, V. J. 2011). Altogether, we notice an exponential growth in demand for this program as more and more hospitals wish to participate. Additionally, a broadening of interest has occurred, namely from (solely) physicians to both nurses and other HC staff. However, they share one common goal; speaking the same language and stimulating teamwork in order to provide high quality health care to the patients.

\section{Acknowledgement}

This work has been supported by Nina Jacobs and Ellen Verschooren as program managers, who adapted the program gradually, based on prior feedback. Furthermore, Valérie Brabanders contributed to the study by editing and revising content, as well as providing the graphical design.

\section{References}

Ackerly, D. C., Sangvai, D. G., Udayakumar, K., Shah, B. R., Kalman, N. S., Cho, A. H., ... Dzau, V. J. (2011). Training the next generation of physician-executives: an innovative residency pathway in management and leadership. Academic Medicine, 86(5), 575-579. https:/doi.org/10.1097/ACM.0b013e318212e51b

Arroliga AC, Huber C, Myers JD, Dieckert JP, W. D. (2014). Leadership in health care for the 21st century: challenges and opportunities. AM J Med, 3(127), 246-249. https:/doi.org/10.1016/j.amjmed.2013.11.004

Bennis, W. (1989). Just Managing isn't enough. Why leaders can't lead. Jossey-Bass.

Brennan, B., Henrick, S., \& Monturo, C. (2016). Leadership, defined: What's your style, and how's it actually perceived? Nursing Management, 47(October), 30-38.

Bohmer, R. (2012). The instrumental value of medical leadership Engaging doctors in improving services, 31 .

Claes, N. (2016). Leiderschap in de gezondheidszorg. Van Theorie naar Praktijk. (1st ed.). Acco.

Daly, J., Jackson, D., Mannix, J., Davidson, P., \& Hutchinson, M. (2014). The importance of clinical leadership in the hospital setting. Journal of Healthcare Leadership, 75. https:/doi.org/10.2147/JHL.S46161

Darzi, A. (2010). A Time for Revolutions - The Role of Clinicians in Health Care Reform. The New England Journal of Medicine, $8(1)$, e8(1-2).

Frank, J. R., Frank, J. R., \& Danoff, D. (2007). The CanMEDS initiative: Implementing an outcomes-based framework of physician competencies The CanMEDS initiative : implementing an outcomes-based framework of physician competencies. Medical teacher, (October), 642-647. https:/doi.org/10.1080/01421590701746983

Heifetz RA. (1994). Leadership Without Easy Answers. The Belknap Press of Harvard University Press.

James K. Stoller. (2009). Developing Physician-Leaders: A Call to Action. Journal of General Internal Medicine, 24(7), 876-878. https:/doi.org/10.1007/s11606-009-1007-8

Kotter, J. P. (1998). What leaders really do. Harvard Business Review Press.

Mountford, J., Webb, C. (2008). Clinical Leadership: Unlocking high performance in healthcare. McKinsley Quarterly.

Mountford, J., Webb, C. (2009). When Clinics Lead. McKinsley Quarterly.

Robbins Beverly, D. R. (2007). Transformational Leadership in Health Care Today. Health Care Manager, 26(3), 234-239. https:/doi.org/10.1097/01.HCM.0000285014.26397.e7 
Schwartz Richard W, Pogge, Caroline R., Gillis, Susan A., Holsinger, J. W. (n.d.). PhD Programs for the Development of Physician Leaders: A Curricular Process in Its Infancy Academic Medicine. Academic Medicine, 75(2), 133-140.

Stoller, K. (2013). Commentary: Recommendations and Remaining Questions for Health Care Leadership Training Programs. Academic Medicine, (88), 12-15. https:/doi.org/10.1097/ACM.0b013e318276bff1

Storey, J., \& Holti, R. (2013). Towards a New Model of Leadership for the NHS, (June).

Sturmberg, Joachim P., Martin, C. M. (2013). Handbook of Systems and Complexity in Health: Chapter 1. https:/doi.org/10.1136/bmj.322.7301.1536

Swanwick, T., \& McKimm, J. (2011). What Is Clinical Leadership and why Is It Important? The Clinical Teacher, 8, 22-26. https:/doi.org/10.1136/bmj.322.7301.1536

Taylor, C. a., Taylor, J. C., \& Stoller, J. K. (2009). Physician-leaders: Views of aspiring and established physician-leaders. Journal of General Internal Medicine, 24(10), 1130-1134. https:/doi.org/10.1007/s11606-009-1091-9

Tomey, A. M. (2009). Nursing leadership and management effects work environments. Journal of Nursing Management, 17(1), 15-25. https:/doi.org/10.1111/j.1365-2834.2008.00963.x

Van der Wal, M. A., Scheele, F., Schönrock-Adema, J., Jaarsma, A. D. C., \& Cohen-Schotanus, J. (2015). Leadership in the clinical workplace: what residents report to observe and supervisors report to display: an exploratory questionnaire study. BMC Medical Education, 15(1). https:/doi.org/10.1186/s12909-015-0480-5

Varkey, P., Peloquin, J., Reed, D., Lindor, K., Harris, I. (2009). Leadership curriculum in undergraduate medical education: A study of student and faculty perspectives. Medical Teacher, 224-250. https:/doi.org/10.1080/01421590802144278 